\title{
Head-Direction Cells Recorded from the Postsubiculum in Freely Moving Rats. II. Effects of Environmental Manipulations
}

\author{
Jeffrey S. Taube, Robert U. Muller, and James B. Ranck, Jr. \\ Department of Physiology, SUNY Health Sciences Center at Brooklyn, Brooklyn, New York 11203
}

The discharge characteristics of postsubicular head-direction cells in a fixed environment were described in the previous paper (Taube et al., 1990). This paper reports changes in the firing properties of head-direction cells following changes in the animal's environment. Head-direction cells were recorded from rats as they moved freely in a $76-\mathrm{cm}-$ diameter gray cylinder. A white card, occupying $100^{\circ}$ of arc, was taped to the inside wall of the cylinder and served as the major orienting spatial cue in the animal's environment.

Rotation of the cue card produced near-equal rotation in the preferred firing direction of head-direction cells, with minimal changes in peak firing rate, directional firing range, or asymmetry of the firing-rate/head-direction function. Card removal had no effect on peak firing rate or range of firing, but in $8 / 13$ cells the preferred direction rotated by at least $24^{\circ}$. Similarly, changing the shape of the environment to a rectangular or square enclosure caused the preferred firing direction to rotate by at least $48^{\circ}$ for $8 / 10$ cells in the rectangle and $3 / 8$ cells in the square, with minimal changes in the peak firing rate or directional firing range. Hand holding the animals and moving them around the cylinder had no effect on the preferred direction or firing range of the cell, but decreased the maximal firing rate in 7/9 cells. On 2 occasions, 2 head-direction cells were recorded simultaneously. The rotation of the preferred firing direction for one cell was the same as the rotation of the preferred direction for the second cell after each environmental manipulation.

These results demonstrate that specific visual cues in the environment can exert control over the preferred firing direction and indicate that head-direction cell firing is not a simple sensory response to visual cues, but rather represents more abstract information concerning the animal's spatial relationship with its environment. The constancy of the angle between the preferred firing directions of pairs of simultaneously recorded head-direction cells suggests that there is a fixed mapping of the population onto direction within the environment. Thus, environmental manipulations appear to cause only a change in the reference direction, but leave all other discharge characteristics of directional cells unchanged. In the discussion, comparisons are drawn

Received May 12, 1989; revised Aug. 16, 1989; accepted Aug. 17, 1989.

This research was supported by NIH grants NS 07117, NS 14497, and NS 20686 .

We wish to acknowledge John L. Kubie for his helpful comments throughout the course of this research. We also thank Larry Eberle for help in designing and constructing the 2-spot tracking system.

Correspondence should be addressed to Dr. Jeffrey S. Taube, Department of Psychobiology, University of California at Irvine, Irvine, CA 92717.

Copyright (c) 1990 Society for Neuroscience $0270-6474 / 90 / 100436-12 \$ 02.00 / 0$ between the responses of head-direction cells and hippocampal place cells to similar environmental manipulations (Muller and Kubie, 1987), and ways in which these 2 spatial systems interact in navigation are discussed. Our findings show that head-direction cells signal the animal's directional heading within an environment and, as such, would be ideal for serving as part of a navigational system.

The preceding paper described the firing properties of postsubicular head-direction cells recorded in freely moving rats placed in a fixed environment (Taube et al., 1990). Head-direction cells were observed to discharge as a function of the animal's head direction in the horizontal plane (azimuth-specific firing), independent of the animal's behavior and location in the environment. For each head-direction cell there was a single preferred direction at which firing was maximal and vectors in the direction of maximal firing were parallel throughout the apparatus. The firing rate increased linearly from near zero to the maximum as the animal's head approached the preferred direction from either side. The angular range of elevated discharge was approximately $90^{\circ}$.

The environmental factors that influence the preferred direction and firing rate of head-direction cells remain to be determined. For azimuth-specific firing to be reliable, the animal must use at least one of the many asymmetries in the environment for orientation. The main purpose of the present study was to change various aspects of the environment in order to identify stimuli that can influence the firing properties of headdirection cells. The types of environmental manipulations selected were the same as those used by Muller and Kubie (1987) in their study of place cells, thereby permitting a direct comparison between the firing properties of place cells and headdirection cells.

In the fixed environment described in the previous paper (Taube et al., 1990), the primary visual cue that provided information for angular reference (orientation) was the large white card taped to the inside wall of the cylinder. Because previous studies had demonstrated that rotation of the white card caused equal rotations of place cell firing fields (Muller and Kubie, 1987), we tested the effects of card rotation on the preferred firing direction of head-direction cells. We will show that rotation of the white card causes equal rotation in the preferred firing direction. Since the cue card controlled the preferred direction in rotation experiments, in the second set of experiments head-direction cells were monitored in the cylinder after removal of the cue card.

Another interesting issue is the effect of a different-shaped environment on directional cell activity. Previous studies have shown that hippocampal place cell firing often changes in strik- 
ing ways when an animal is put into a new or different environment (Kubie and Ranck, 1983; Best and Thompson, 1984; Muller and Kubie, 1987; Breese et al., 1989). For example, Muller and Kubie (1987) found that place cells recorded from an animal in a square enclosure had altogether different firing fields when compared to firing fields of the same neurons recorded in the cylinder, despite the fact that both chambers were in the same location within the laboratory and both chambers contained a white card in the same location relative to the room. To determine whether directional cells share these same characteristics, in the third set of environmental manipulations we monitored directional cell activity when animals were placed in either a rectangular or square enclosure (instead of the cylinder). We will show that altering the shape of the environment leads only to changes in the preferred firing direction, with minimal changes in other firing properties. In 2 cases it was possible to record simultaneously from a pair of directional cells as the environment was altered. Under these conditions, it was possible to examine several properties of the directional cell network.

An additional purpose of this paper was to show that directional cell firing can be uncoupled from the animal's behavior. The previous paper (Taube et al., 1990) reported that direct observations revcalcd no compclling correlation between directional cell firing and the animal's behavior, which consisted mostly of walking around in the apparatus. In the final set of experiments, head-direction cells were monitored while the animal's movements were restricted and it was carried by hand within the cylinder or to different portions of the laboratory.

Our general conclusion is that directional cell firing is neither sensory- nor motor-like, but rather is related to an aspect of the animal's spatial relationship with its environment. In this way, head-direction cells are similar to place cells. Furthermore, the existence of head-direction cells implies that the neural network involved in solving spatial problems is not confined to the hippocampus. The nature of the spatial information encoded by head-direction cells makes them well-suited for serving as a component in a navigational system.

Preliminary reports concerning some of these findings have been presented (Taube et al., 1987, 1988).

\section{Materials and Methods}

The methods used were similar to the ones described in the previous paper (Taube et al., 1990), which gives a detailed description of the behavioral training, electrode construction, surgical techniques, and recording procedures. The methods described below pertain only to the experiments concerned with different environmental conditions.

Behavioral training and apparatuses. Long-Evans female rats were trained to retrieve food pellets scattered into a $76-\mathrm{cm}$-diameter, $51-\mathrm{cm}$ high gray cylinder. A white sheet of cardboard, $51 \mathrm{~cm}$ high and occupying $100^{\circ}$ of arc, was taped onto the inside wall of the cylinder at 3 o'clock (as viewed by an overhead video camera) and provided the sole intentional cue for spatial orientation. Two other apparatuses were used to examine the effects of environmental shape changes on cell firing. One apparatus was a rectangle, $46 \times 57 \mathrm{~cm}, 51 \mathrm{~cm}$ high; the second was a squarc $69 \times 69 \mathrm{~cm}, 51 \mathrm{~cm}$ high. Both apparatuses were gray and had a white card entirely covering 1 of the 4 inside walls; the card was usually positioned on the wall corresponding to 3 o'clock as seen from overhead. For the rectangular enclosure, the short sides of the rectangle were positioned at the 3 and 9 o'clock positions. The floor of all 3 apparatuses was composed of a replaceable sheet of gray background paper.

To encourage the animals to use the white card for orientation, several precautions were taken to minimize information from other nonuniformities in the environment. First, to limit the use of olfactory cues normally available to a rat, the floor paper was replaced with a new sheet prior to each recording session. Second, recording sessions were done in a small room with the door closed to limit auditory cues. Third, to control the visual environment, a continuous floor-to-ceiling curtain surrounded the apparatus during a recording session.

Units. Electrical signals from individual units were recorded, amplified, and discriminated as previously described. All head-direction cells discussed below were among the 25 units used for the quantitative analysis in the previous paper.

Recording sessions. When a head-direction cell was present, the animal was put back in its home cage and the laboratory prepared for a recording session. The animal was returned to the laboratory in an opaque box. The box was carried around the apparatus while it was simultaneously rotated about a vertical axis (in the horizontal plane) Following 2-3 revolutions around the apparatus, the box was opened, the recording cable connected to the animal's headstage, and the animal placed in the apparatus. Care was taken to put the animal into the apparatus from a different point at the start of each recording session. In addition, the experimenter left the curtained area in a different direction each time.

During an 8-min recording session, an automatic video/computer system tracked the animal's position and head direction every $1 / 60$ th sec while cell firing was simultaneously monitored. Following completion of a session, the animal was disconnected from the recording cable, put back into the carrying box, and returned to its home cage. If another recording session was to be conducted, the floor paper was replaced, the animal brought back to the laboratory room in the box, and the procedure for introducing it into the apparatus repeated. If at any time the unit's waveform changed, so that the cell was not well isolated, the experiment was halted.

Card rotation experiments. A card rotation experiment consisted of first monitoring the cell's activity during a standard session in the cylinder with the white cue card at 3 o'clock. The animal was returned to its home cage, the floor paper was replaced, and the cue card rotated by 90,180 , or $270^{\circ}$. After preparation of the apparatus, the animal was returned to the laboratory room and another 8-min recording session was run. Following completion of the card rotation session, the card was returned to its standard ( 3 o'clock) position and a second control session was run to check for reversibility of the effects observed in the card rotation session.

Card removal experiments. The activity of many head-direction cells was monitored after the card was removed from the cylinder; the removal was always done when the animal was in its home cage. A card removal session was always preceded and followed by a standard session.

Enclosure shape change experiments. To examine the effects of changing the apparatus shape on neuronal discharge, recordings were made with the animal in either a rectangular or square enclosure. Since presurgical behavioral training and cell screening were conducted in the cylinder, the animal's first exposure to the rectangular or square enclosure occurred when the first head-direction cell for a given animal was tested in the different cnclosures.

Recording session sequence. Recording session sequences for all cells began with a "standard" session in the cylinder with the cue card positioned at 3 o'clock. Sessions were usually conducted in the following sequence:
1. Standard scssion
2. Card rotation
3. Standard session
4. Card removal
5. Standard session
6. Session in rectangle
7. Standard session
8. Session in square
9. Standard session

On 2 occasions, the final session in the cylinder (session \#9) was conducted with the cue card rotated. For 5 experiments, a recording session was inserted after either the rectangle or square session, where the cue card was rotated in the rectangle or square. The alternations of standard sessions and manipulated sessions allowed us to check the stability of the preferred direction in standard sessions following environmental manipulations.

Hand-held sessions. For some cells, following either the initial or final 8-min standard session, the animal was held in the experimenter's hand and carried around to different portions of the cylinder. Directional cell 

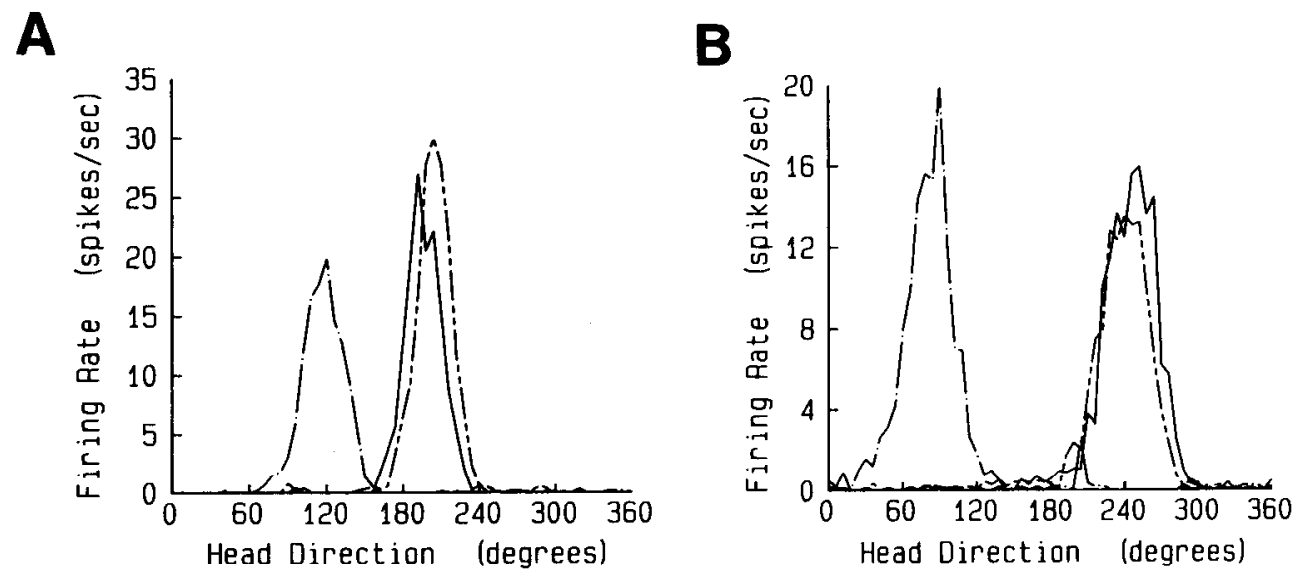

Figure 1. Responses of 2 head-direction cells to rotation of the white cue card in the cylinder. In each case, the firing-rate/head-direction function for the cell was first recorded with the card in its standard position at 3 o'clock (solid lines). The animal was removed from the cylinder while the card was rotated and the floor paper replaced. A second session was then run with the card at the new angle; the rotation was $90^{\circ}$ clockwise in $A$ and $180^{\circ}$ in $B$. In response, the preferred firing direction of each cell rotated by approximately the same amount (dash-dot lines). When the card was returned to its initial position, the preferred directions also reverted to their original values (lines with 2 short dashes). Note that in $A$ the rotation session was associated with a decreased peak firing rate, whereas in $B$ the peak rate increased during the rotated session. As described in the text and in Table 1, no consistent change of any parameter of directional cell firing, except preferred direction, was caused by changing the environment. The results of $A$ and $B$ are from different animals.

activity was then monitored for $1 \mathrm{~min}$ while the animal was rotated by hand in the horizontal plane. In addition, for many cells, the animal was hand-carried to different portions of the laboratory room while the audio output of cell firing was monitored continuously.

Data analysis. Data analysis was performed off-line at a later time. Head directions were sorted into 60 bins, each bin representing $6^{\circ}$ of arc. For each bin, the total time spent at that head direction and the number of spikes discharged were summed. Dividing the number of spikes by the amount of time spent in each bin yielded the bin firing rate. Head direction vs. firing rate plots were constructed for each recording session. The firing characteristics of head-direction cells (preferred firing direction, peak firing rate, directional firing range, and asymmetry score) were obtained using the same procedures described previously (Taube et al., 1990).

\section{Results}

\section{Effects of card rotation}

The major polarizing cue (i.e., orienting reference) in the apparatus was the white card taped on the inside cylinder wall. The salience of the card for head-direction cell firing was tested by rotating the angular position of the card relative to the laboratory frame. If the card exerted stimulus control over directional cell firing, the preferred direction should rotate equally.
The results of a typical rotation experiment are shown in Figure $1 \mathrm{~A}$. In the first recording session, when the card was centered at 3 o'clock (as viewed from overhead) the preferred direction was $192^{\circ}$ (solid line). In the second session, after the card was detached from the wall and reattached at 6 o'clock, the preferred direction rotated to $120^{\circ}$ (dash-dot line). Thus, the preferred direction rotated $72^{\circ}$ in the same direction as the card. In the final session, when the card was returned to its initial position (i.e., 3 o'clock), the preferred direction returned to its original value (line with 2 short dashes). Figure $1 B$ shows the effects of a $180^{\circ}$ card rotation on the preferred direction of a second cell. In this case, the preferred direction rotated $162^{\circ}$ clockwise.

Similar results were observed for $19 / 21$ head-direction cells tested for card rotation; the 2 exceptional cells are discussed later. Eight experiments were done with the card rotated $90^{\circ}, 4$ experiments with the card rotated $180^{\circ}$, and 9 experiments with the card rotated $270^{\circ}$. In 4 experiments a new card was used during the rotation session; in all cases, the preferred firing direction rotated nearly equally with the card, indicating that control was exerted by the overall appearance of the card rather than with a particular detail.

\section{Table 1. Mean absolute changes in directional firing parameters following environmental manipulations}

\begin{tabular}{|c|c|c|c|c|c|c|}
\hline Session type comparison & $n$ & $\begin{array}{l}\text { Correlation coefficient } \\
r \text { :range }\end{array}$ & $\begin{array}{l}\text { Preferred firing } \\
\text { direction (degrees) }\end{array}$ & Peak firing rate (\%) & $\begin{array}{l}\text { Directional firing } \\
\text { range }(\%)\end{array}$ & $\begin{array}{l}\text { Asymmetry ratio } \\
(\%)\end{array}$ \\
\hline Std $1 /$ Std 2 & 15 & $0.979: 0.750-0.996$ & $6.6 \pm 1.3$ & $97.1 \pm 7.1$ & $97.4 \pm 3.5$ & $90.9 \pm 4.6$ \\
\hline Stdl/rotation & 19 & $0.978: 0.775-0.998$ & $17.1 \pm 3.0^{a}$ & $99.9 \pm 7.1$ & $97.0 \pm 3.9$ & $125.3 \pm 24.8$ \\
\hline Std1/card removal & 13 & $0.983: 0.904-0.998$ & $31.4 \pm 8.2$ & $97.6 \pm 5.8$ & $109.7 \pm 5.6$ & $112.2 \pm 7.3$ \\
\hline Std1/rectangle & 10 & $0.983: 0.949-0.997$ & $83.3 \pm 15.6$ & $96.3 \pm 9.5$ & $101.1 \pm 3.8$ & $93.9 \pm 6.3$ \\
\hline Stdl/square & 8 & $0.981: 0.901-0.996$ & $45.4 \pm 22.5$ & $80.6 \pm 8.1$ & $99.8 \pm 2.6$ & $112.4 \pm 16.7$ \\
\hline Std1/hand-held & 9 & $0.901: 0.737-0.965$ & $9.9 \pm 3.0$ & $69.1 \pm 11.2^{b}$ & $116.5 \pm 12.2$ & $94.0 \pm 12.2$ \\
\hline
\end{tabular}

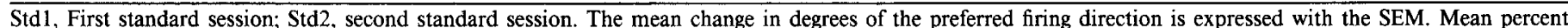

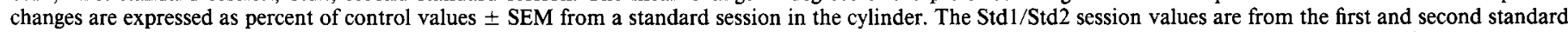

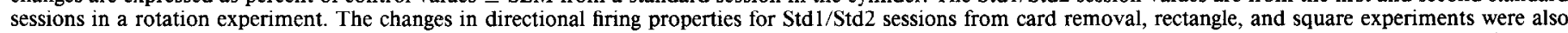

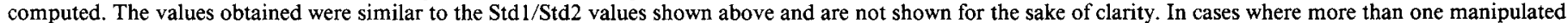
session was recorded from the same cell, the session with better cell isolation was used for computing the mean values.

${ }^{a}$ Value reported is the directional deviation from the expected preferred firing direction.

${ }^{b} t=2.75 ; d f=8 ; p<0.05$. 


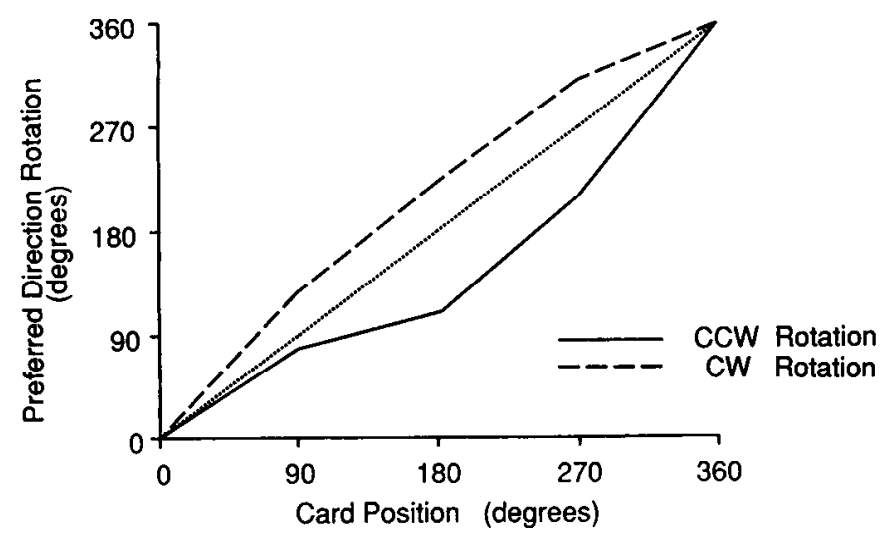

Figure 2. Series of multiple card rotations conducted while the animal was in the cylinder. The effects of 2 series of card rotations on the same head-direction cell are shown. On the $X$ axis, 0 or $360^{\circ}$ corresponds to the standard ( 3 o'clock) position of the card, and $90^{\circ}$ corresponds to the 12 o'clock card position. The $Y$ axis shows the rotation of the cell's preferred direction away from its position with the card at 0 or $360^{\circ}$. The dotted line shows what is expected for perfect following of the card position by preferred direction. The solid line shows the effects of a series of $90^{\circ}$ counterclockwise rotations, starting at $0^{\circ}$ and ending at $360^{\circ}$. Note that the preferred direction rotation is always less than the expected amount until the card is back at its initial position. The dashed line shows the effects of a series of $90^{\circ}$ clockwise rotations, starting at $360^{\circ}$ and ending at $0^{\circ}$. Note that the preferred direction rotation again is always less than the expected amount until the card is back at its initial position.

Although the preferred direction "followed" card rotations, other parameters, such as peak firing rate, directional firing range, and asymmetry score, did not change. For each head-direction cell, the peak firing rate, directional firing range, and asymmetry ratio from a rotated session, or a second standard session, were expressed as a percent of the values obtained in the first standard session. The mean percent changes for peak firing rate, directional firing range, and asymmetry ratio from a standard session to either a rotated or second standard session are shown in Table 1 .

Although the rotation of the preferred direction was usually similar to the rotation of the cue card, the control over preferred direction by the card was not perfect. The deviation from the expected rotation of preferred direction was calculated for each head direction as follows. First, the cross-correlation between the firing-rate/head-direction functions for the standard and rotated sessions was calculated. In general, this cross-correlation was negative, because there was little, if any, overlap of the angular range of elevated firing. Next, the firing-rate/head-direction function for the rotated session was shifted clockwise in $6^{\circ}$ steps, and the cross-correlation recalculated at cach stcp. The rotation of preferred direction was defined as the angle at which the cross-correlation was maximal; if the rotation of preferred direction were perfect, the maximum cross-correlation would be found at the angular position to which the card was rotated. The maximal cross-correlation between standard and card-rotation session pairs was almost always greater than 0.90 (Table 1). This indicated that the shapes of the 2 firing-rate/head-direction functions were similar. In addition, Table 1 shows that the maximal cross-correlation was nearly the same for standard/ rotation session pairs and standard/standard session pairs.

The mean absolute deviation from the expected rotation for the 19 cells showing rotation was $18.9 \pm 2.7^{\circ}$ (SEM), range: $6-$ $48^{\circ}$. When the absolute deviations were obtained from the pre-

\begin{tabular}{|c|c|c|c|c|}
\hline Animal & Unit & $\begin{array}{l}\text { Card removal } \\
\text { (degrees) }\end{array}$ & $\begin{array}{l}\text { Rectangle }^{a} \\
\text { (degrees) }\end{array}$ & $\begin{array}{l}\text { Square }^{a} \\
\text { (degrees) }\end{array}$ \\
\hline 1 & 1 & -108 & {$[+66]$} & \\
\hline 2 & 1 & -42 & +96 & \\
\hline 2 & 2 & $-42(-48)$ & $+84(+90)$ & $-12(+48)$ \\
\hline 2 & 3 & $-30(-48)$ & +90 & +48 \\
\hline 2 & 4 & 0 & +78 & +6 \\
\hline 2 & 5 & +6 & +90 & +6 \\
\hline 2 & 6 & +6 & +78 & -6 \\
\hline 3 & 1 & $+48(+96)$ & & \\
\hline 3 & 2 & $+48(+78)$ & & \\
\hline 4 & 1 & +6 & +12 & \\
\hline 5 & 1 & +6 & +114 & +108 \\
\hline 5 & 2 & & 180 & +174 \\
\hline 6 & 1 & +66 & & \\
\hline 6 & 2 & +24 & +6 & +12 \\
\hline
\end{tabular}

Values in parentheses show results from a second recording session. The cue card was positioned at $3 \mathrm{o}^{\prime} \mathrm{clock}$ for the sessions in the square and rectangular enclosures. The value shown in brackets for a rectangle session indicates the change in the preferred direction when the cue card was first positioned at $120^{\prime}$ clock (i.e., $90^{\circ}$ rotation).

${ }^{a}+$ indicates a counterclockwise rotation; - indicates a clockwise rotation.

ferred directions in standard and rotated sessions based on the triangular model (see Taube et al., 1989), the mean deviation $\left[17.1 \pm 3.0^{\circ}\right.$ (SEM)] was nearly identical. The distribution of deviations from the expected rotation for the 16 cells tested with a card rotation of 90 or $270^{\circ}$ showed no strong trend for either underrotation ( 10 cells) or overrotation ( 6 cells). Thus, the cue card exerted stimulus control over the preferred firing direction, although the control was detectably impcrfect.

When the card was returned to its initial position, the preferred firing direction returned to near its original value. The mean absolute deviation for pairs of standard sessions was 6.6 $\pm 1.3^{\circ}$ (SEM), range: $0.5-15.1^{\circ}, n=15$. A $t$-test showed that the deviation for standard sessions was lower than for rotated sessions $(t=3.10 ; d f=32 ; p<0.01)$. Furthermore, an $F$-test showed that the preferred direction was more variable following cue card rotations $(F=6.57 ; d f=18 ; p<0.001)$. This suggests that features of the environment besides the cue card act as determinants of the preferred firing direction.

For 2 directional cells, a series of card rotations was conducted while the animal was in the cylinder and able to watch the card being rotated. In both cases, the card was initially at the 3 o'clock position and was rotated in $90^{\circ}$ steps until it returned to its original position. To a first approximation, the preferred direction of both cclls rotated along with the card. On the 4 occasions that rotations were done with the animal in the cylinder, however, there was a consistent underrotation of the preferred direction each time the card was rotated. In 2 cases, the preferred direction returned to within $6^{\circ}$ of its starting value once the card returned to the 3 o'clock position. Both of these examples, done on the same directional cell, are shown in Figure 2. The dashed line in Figure 2 shows the results from a series of clockwise (CW) rotations, whereas the solid line is for a series of counterclockwise $(\mathrm{CCW})$ rotations. The points for the $\mathrm{CW}$ and $\mathrm{CCW}$ rotations lie on opposite sides of the dotted line, which indicates perfect following of rotation. This result suggests a form of hysteresis and is a second indication that the control exerted by the card is not the sole determinant for the preferred firing direction. 


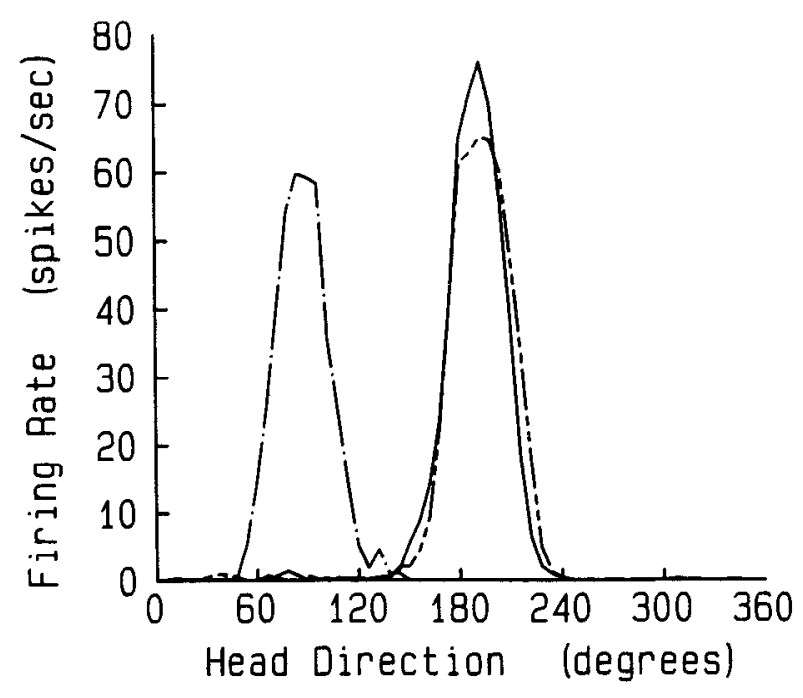

Figure 3. Effects of removing the cue card on the discharge characteristics of a head-direction cell. The solid line shows the firing-rate/ head-direction plot with the card in its standard 3 o'clock position. When the card was removed, the firing properties of this cell were largely unaffected except for a counterclockwise rotation of about $120^{\circ}$ in the preferred direction (dash-dot line). When the card was replaced in the cylinder, the preferred direction returned to its original value (line with 2 short dashes). In each case, the animal was removed from the cylinder between each recording session.

\section{Effects of card removal}

The card rotation experiments indicate that the card exerts control over directional cell firing. To investigate the nature of the control, we monitored directional cell firing following removal of the card from the cylinder. Several outcomes were possible under this condition. The cell might cease to fire or fire at a constant rate, independent of head direction. Alternatively, the peak rate could decrease or the background rate might increase. Finally, if a preferred direction still exists, it might rotate relative to the preferred direction observed with the card in its standard position.

For 13 cells in 6 animals, card removal led only to an unpredictable shift in the preferred direction. Peak firing rate, firing range, and asymmetry were unaffected (see Table 1). In particular, it was never observed that a cell ceased firing during a card removal session. An estimate of the rotation in preferred direction caused by card removal was calculated as described above for card rotation experiments. There was no difference in the mean correlation coefficients between standard and card removal sessions or pairs of standard sessions (Table 1). Table 2 shows that in $8 / 13$ card removal experiments the preferred firing direction rotated at least $24^{\circ}$. Table 1 shows that the mean absolute shift in the preferred firing direction after card removal was significantly ( $t=14.20, d f=11, p<0.005$ ) greater than the mean absolute shift observed between pairs of standard sessions. There was no trend for the preferred firing direction to rotate clockwise or counterclockwise after card removal. Except for 2 cells not included in the above analysis, standard sessions conducted after card removal sessions showed that the preferred direction returned to the value observed in the initial standard session. The 2 exceptions are discussed below. The results from a typical cue card removal session are shown in Figure 3.
A second card removal session was done on 4 cells. As shown in Table 2, the absolute deviations in the preferred direction between the 2 card removal sessions were $6,18,30$, and $48^{\circ}$, with a mean of $25.5^{\circ}$. Statistical testing was not warranted with only 4 cases, but the mean absolute deviation between card removal sessions was not much greater than the mean absolute deviation of $18.9^{\circ}$ observed when standard and card rotation experiments were compared.

Table 2 also shows the effects of card removal for 6 cells recorded from one animal. For the first 3 cells (units \#1-3), the preferred directions rotated between 30 and $48^{\circ}$ clockwise; for the last 3 cells (units \#4-6), the preferred direction rotated clockwise between 0 and $6^{\circ}$ from the standard session. The variations in preferred direction shifts within the same animal suggest that the secondary cues used to anchor the directional coordinate were not the same for all sessions, but were consistent for sequences of card removal sessions.

\section{Effects of changing the environmental shape}

Until now, head-direction cell firing has been described while the animal was in a cylinder. In this section we consider the effects on directional cell firing when recordings were done in a rectangular enclosure ( 10 cells) or in a square enclosure ( 8 cells). For each enclosure a white card was attached to the wall corresponding to 3 o'clock as seen from overhead; this position corresponded to the position of the white card in the cylinder. The changes in preferred direction for both manipulations are shown in Table 2 . For the rectangular enclosure, $8 / 10$ headdirection cells changed their preferred firing direction by at least $78^{\circ}$. It was noteworthy that the change in the preferred direction always occurred in a counterclockwise direction; the reason for this was unclear. In one animal, 6 different head-direction cells were monitored in the rectangle. Interestingly, the preferred direction always rotated between $78^{\circ}$ and $96^{\circ}$, suggesting that the features of the environment used for orientation during each exposure to the rectangle were constant. A single head-direction cell in a different animal was initially monitored in the rectangle with the long axis of the rectangle at the 6 and 12 o'clock positions, and the cue card placed at the 12 o'clock position. Under these conditions the preferred direction rotated $66^{\circ}$ counterclockwise.

Standard sessions in the cylinder done after rectangle sessions showed that the preferred direction returned to its original value. In contrast to the changes in preferred direction, Table 1 shows there were no significant changes in the peak firing rate, directional firing range, or asymmetry ratio during rectangle sessions.

After a standard session following the session in the rectangle, 8 cells were further tested by placing the animal in the square enclosure. The results from this manipulation (Table 2) were similar to those for the rectangular enclosure; the preferred direction changed for $3 / 8$ cells, but the other properties (peak firing rate, directional firing range, asymmetry ratio) were constant. One cell, which showed only a $12^{\circ}$ clockwise rotation in the preferred direction when initially tested in the square enclosure, showed a $48^{\circ}$ counterclockwise rotation during a second square session the next day. In 6 cells tested with a standard scssion after recording in the square, the preferred direction returned to its original value. For 2 other cells tested in the square, the second cylinder session was done with the cue card rotated $(90$ or $180^{\circ}$ ). In both cases, the preferred direction maintained its relationship to the position of the cue card observed during the previous standard session; the deviations in the preferred di- 
A

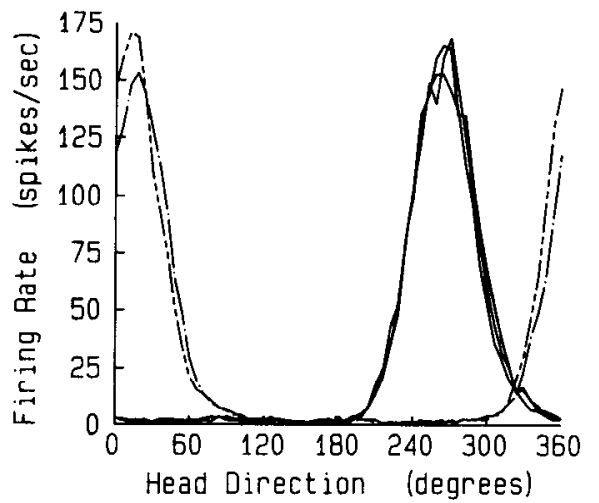

B

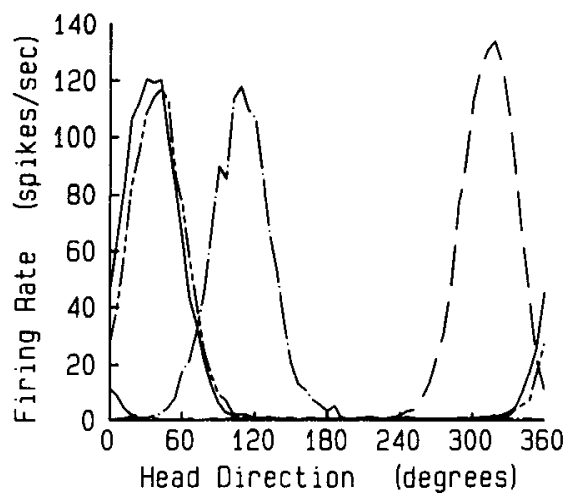

Figure 4. Head direction vs. firing rate graphs for 2 experiments in different shaped enclosures. A, The solid lines show the results from standard sessions in the cylinder (sessions $\# 1,3,5$ ) before and after recording sessions in a rectangular enclosure (session \#2, dash-dot line) or square enclosure (session \#4, line with 2 short dashes). In the sessions with the rectangle and square, the preferred head direction rotated 114 and $108^{\circ}$ counterclockwise, respectivcly, with no changes in the peak firing rate or directional firing range. $B$, Results from a different cell in another animal. The solid line shows the results from a standard session in the cylinder (session \#1). The dash-dot line shows the results from a session in the rectangle (session \#2) and the line with 2 short dashes shows the results from a session in the square (session \#4). In the rectangle session the preferred direction rotated $78^{\circ}$ counterclockwise, with no change in the peak firing rate or directional firing range. For the square enclosure session, there was no change in preferred direction, peak firing rate, or directional firing range compared to the session conducted in the cylinder. When the square and cue card were rotated $270^{\circ}$ (session \#5, long dashed line) the preferred firing direction rotated the same amount as the card rotation. Not shown for the purpose of clarity are the results from standard sessions in the cylinder (sessions \#3 and \#6) which were run between the sessions in the rectangle and square, and following the card rotation in the square. The results from both standard sessions were similar to the first standard session shown in the graph. Except for the card rotation session in $B$ (session \#5), all sessions had a cue card at the 3 o'clock position (as viewed by an overhead video camera) and both the rectangular and square enclosures were placed in the same corresponding location as the cylinder.

rection from the card rotation were -12 and $-24^{\circ}$ (i.e., underrotations).

The results from recordings in rectangular and square enclosures showed that for individual cells, changes in the preferred direction in 1 enclosure were not necessarily identical to the changes observed in the other enclosure. In fact, the preferred direction differed by at least $36^{\circ}$ in $5 / 8$ cases. The results for 2 cells recorded in all 3 apparatuses are shown in Figure 4. In addition, Table 2 shows that the preferred directional changes observed in the rectangle and/or square were usually different from the amount of rotation in the preferred direction for the card removal experiments.

To determine whether the cue card exerted control over directional firing in the rectangle and square enclosures, 3 rotation experiments were done in the rectangle and 2 in the square. Two of the three rectangle experiments were $90^{\circ}$ rotations of both the enclosure and card; in both cases, the preferred direction rotated $90^{\circ}$. In the third rectangle experiment, only the cue card was rotated $180^{\circ}$ and the preferred firing direction rotated $174^{\circ}$. In both square rotation experiments, the enclosure and card were rotated together $\left(90\right.$ or $\left.270^{\circ}\right)$. The deviations of preferred direction were 0 and $-6^{\circ}$ (underrotation), indicating once again that the card exerts stimulus control. Figure $4 B$ shows the results from one of the rotations conducted in the square enclosure.

We also monitored head-direction cell activity when the animal was in a different cylinder in another recording room. The cylinder used was a copy of the cylinder in the original recording room and contained a white card at the same compass direction. Although it was not possible to use the 2-spot tracker in this case, we observed the animal while listening to the audio output of cell firing. For the 2 cells tested under these conditions, the preferred direction and other discharge characteristics (e.g., peak firing rate, directional firing range) appeared to be similar to those observed in the original recording room.

\section{Hand-held sessions}

In addition to the different shaped environments used above, we also monitored directional cell firing when the animal's

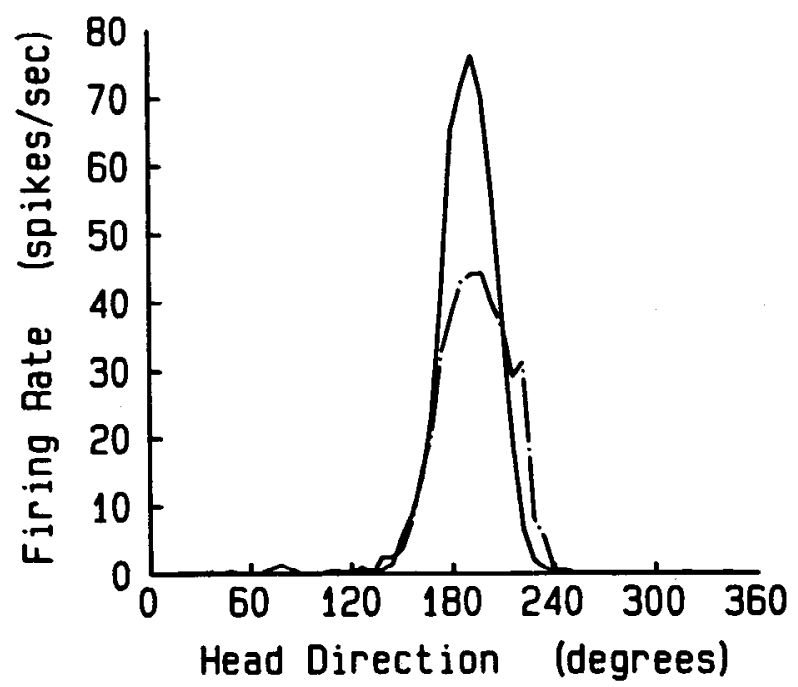

Figure 5. Effects of carrying the animal by hand around the surface floor of the cylinder on the firing characteristics of a head-direction cell. The solid line shows the firing-rate/head-direction function for the cell with the animal moving freely in the apparatus. The dash-dot line shows the firing-rate/head-direction function when the animal was hand-held and both its position and head orientation were changed by moving the animal around in the cylinder. The major effect was a decrease in the cell's firing rate; preferred direction and directional firing range were unaffected. 


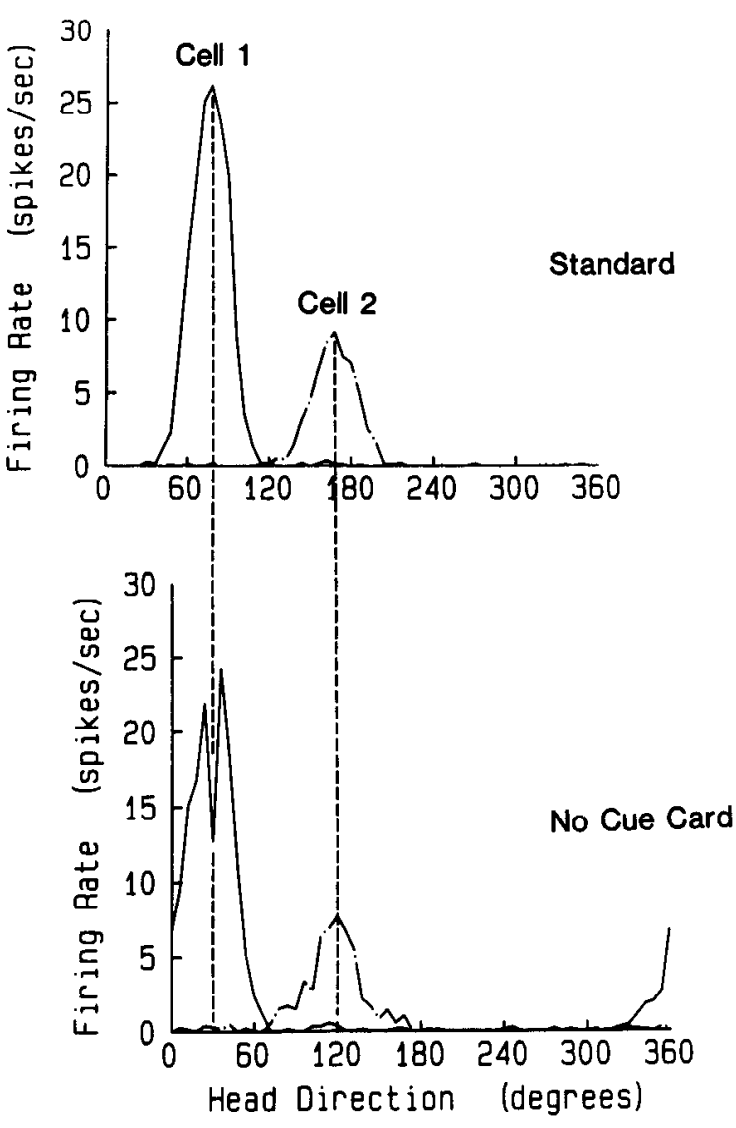

Figure 6. Effects of card removal on the discharge characteristics of a pair of simultaneously recorded head-direction cells. The responses of the same pair of cells to different manipulations are also shown in Figures 7 and 8 . The top plot shows the firing-rate/head-direction functions for both cells with the card in its standard 3 o'clock position. Cell \#1 corresponds to the solid line; cell \#2 corresponds to the dash-dot line. The bottom plot shows the firing-rate/head-direction functions after card removal. The bottom plot has been shifted horizontally along the head-direction axis to show the extent of the preferred direction rotation for cell \# 1 caused by card removal. Note that the preferred direction of cell \#2 during card removal is directly under the preferred direction of cell \#2 during the standard session. This demonstrates that the rotation of preferred direction caused by card removal is equal for the 2 cells.

movements were restricted by hand holding them. One-minute recording sessions were conducted while the experimenter moved the animal to different locations in the cylinder while continually rotating the animal in the horizontal plane. The results from 1-min hand-held sessions showed that the preferred direction and directional firing range remained relatively unchanged (Table 1), but the peak firing rates in the hand-held sessions were decreased in $7 / 9$ cells compared to freely moving sessions. The mean percent of the peak firing rate from a hand-held session compared to a freely moving session was $69.1 \pm 11.2 \%$ (SEM), range: $29.4-142 \%(t=2.75 ; d f=8 ; p<0.05)$. The results from a representative hand-held session and the corresponding freely moving session are shown in Figure 5.

In addition to being carried around in the cylinder, animals were also held $1-1.5 \mathrm{~m}$ above the floor and carried around to different regions of the laboratory within a $1.5-\mathrm{m}$ radius of the cylinder center. Under these conditions, cell activity was monitored by listening to the audio output. Although the view of the environment was dramatically different than when the an- imal was in the cylinder, the preferred direction was constant for all 25 head-direction cells examined.

\section{Simultaneous recording from 2 cells}

Until now, we have reported the effects of environmental manipulations on a cell-by-cell basis. It would be interesting, however, to know if the change observed in preferred direction is different for each cell after a manipulation, or if the change is the same for all cells. The issue of equal shifts in preferred direction across cells can be answered directly by recording from 2 or more cells simultaneously.

We were able to make simultaneous recordings from 2 pairs of cells in 2 animals under several environmental conditions. The cells of each pair had different preferred firing directions. In both cases, the difference in preferred direction between the 2 cells remained nearly constant across all the conditions, even though the preferred direction of each cell changed considerably. Head direction versus firing rate plots for 1 pair of units are shown in Figures 6-8. The top firing-rate/head-direction plot in each figure is for the 2 simultaneously recorded cells from a standard session in the cylinder, whereas the bottom plot is for the same cells recorded during an environmentally manipulated session. For the card removal (Fig. 6), rectangle (Fig. 7), and square (not shown) sessions, the bottom plot was shifted such that the preferred direction of cell \#1 in the manipulated session was aligned directly below the preferred direction of cell \#1 in the standard session (dashed line on left). The shift along the horizontal axis for the lower plots $\left(48^{\circ}\right.$ clockwise for Fig. $6 ; 90^{\circ}$ counterclockwise for Fig. 7) indicates the rotation of cell \#1's preferred direction. A second dashed line was drawn vertically from the preferred direction of cell \#2 in the standard session to the bottom plot. Note that the second line passes through (or close to) cell \#2's preferred direction for the card removal and rectangle sessions, indicating that the preferred direction for cell \#2 rotated the same amount as the preferred direction of cell \#1. For the card removal, rectangle, and square experiments, the difference between rotation of preferred directions for the 2 cells was 0,0 , and $6^{\circ}$, respectively.

Figure 8 shows that the preferred direction of both cells rotated equally after the cue card was rotated $180^{\circ}$. In Figure 8 , the bottom plot was shifted by $180^{\circ}$, the expected rotation of the preferred direction for both cells. Dashed lines were drawn between the peak firing rates of both cells. Note that neither dashed line is vertical, indicating the deviations of the preferred directions from the expected rotations. Although the preferred directions did not rotate $180^{\circ}$, the 2 dashed lines were parallel to one another, indicating that the deviations $\left(24^{\circ}\right)$ were the same for both cells.

A sccond pair of cells in another animal was monitored for 2 card removal sessions. The first card removal produced rotations in the preferred firing direction of $96^{\circ}$ and $78^{\circ}$, an $18^{\circ}$ difference. However, direct observation of cell activity and the animal's head direction suggested that the preferred direction was unstable and changed during the course of the session for unknown reasons. As a result of the instability, the directional firing ranges for both cells increased in this session; the range for one cell was about $200^{\circ}$. Because of the instability in the first session, a second card removal session was done 10 min later without removing the animal from the cylinder. In this session, the preferred directions changed, but the shifts in the preferred directions compared to the standard session were identical $\left(48^{\circ}\right.$ clockwise). A $90^{\circ}$ card rotation session was also conducted on 


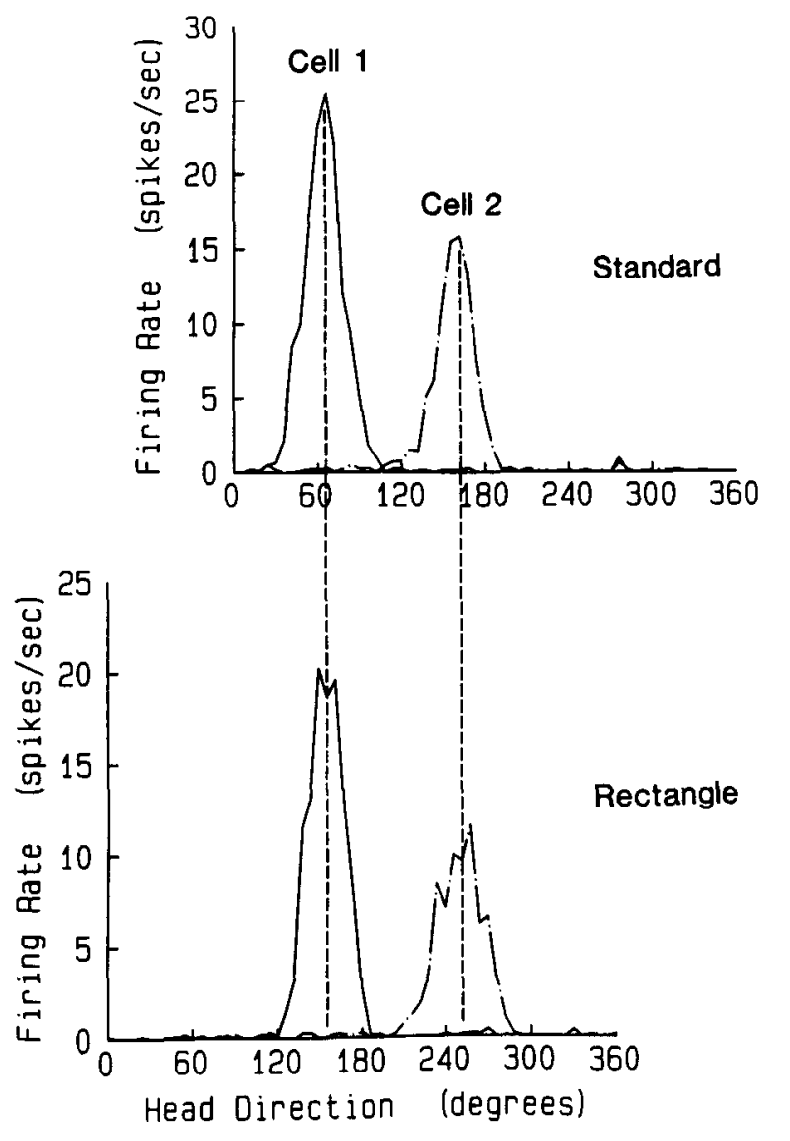

Figure 7. Effects of changing the shape of the apparatus on the firing properties of a pair of simultaneously recorded head-direction cells. The upper plot shows firing-rate/head-direction functions for the 2 cells while the animal is in the cylinder with the white card at its standard 3 o'clock position. Cell \#1 corresponds to the solid line; cell \#2 corresponds to the dash-dot line. The bottom plot shows the firing-rate/head-direction plots for the same cells when the animal was in the rectangle. A white card covered the entire short wall of the rectangle and this wall was positioned at 3 o'clock. The bottom plot is shifted horizontally along the head-direction axis to indicate the rotation of the preferred direction of cell $\# 1$. The preferred direction for cell $\# 2$ is shifted by the same amount, as shown by the vertical dashed line on the right.

this pair of cells. The deviations from the expected rotation were 0 and $-6^{\circ}$ (underrotation), which is consistent with the results from the other pair of simultaneously recorded cells.

\section{Recordings from cells showing aberrant responses}

Although the responses of most head-direction cells to environmental manipulations conformed to the descriptions given above, 4 cells showed aberrant responses. The preferred direction of 2 cells showed little rotation after card rotation $\left(6^{\circ}\right.$ after a $180^{\circ}$ card rotation in one case and $-12^{\circ}$ after a $-90^{\circ}$ rotation in the other). These 2 cells were recorded from different animals, but the other 3 cells recorded from each animal showed strong stimulus control by the cue card in rotation experiments. One of the 2 cells which was insensitive to card rotation was the cell not included in the quantitative analysis in the previous paper (Taube et al., 1990). This cell was first recorded while the animal chewed and pulled on the cue card until it fell to the floor. Although there was nothing unusual about its observed peak firing rate (31.04 spikes/sec) or asymmetry ratio (1.44), it had

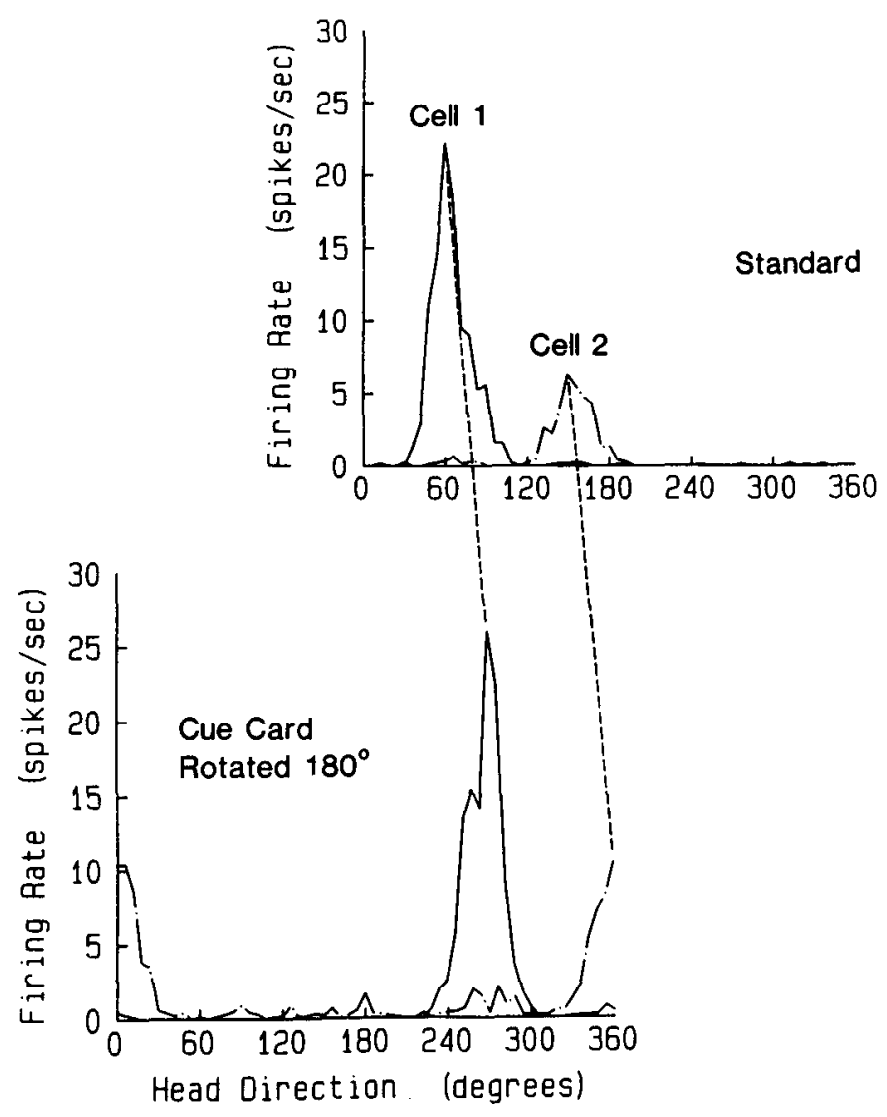

Figure 8. Effects of card rotation in the cylinder on the discharge characteristics of a pair of simultaneously recorded head-direction cells. The top plot shows the firing-rate/head-direction functions for both cells with the card in its standard 3 o'clock position in the cylinder. Cell \#1 corresponds to the solid line; cell \#2 corresponds to the dash-dot line. The bottom plot shows the firing-rate/head-direction functions after the white card was rotated $180^{\circ}$. The bottom plot has been shifted $180^{\circ}$ along the head-direction axis. The imperfect following of the card position by the preferred direction for cell \#1 is indicated by the slope of the left dashed line. Note that the right dashed line that connects the preferred direction of cell \#2 during the standard and rotated sessions has the same slope as the line for cell \#1. This result indicates that the rotation of preferred direction is equal for the 2 cells, even though it is imperfect for both.

the largest directional firing range $\left(166.5^{\circ}\right)$ of any head-direction cell observed.

Two other cells were not considered above in the card removal experiments because their preferred direction was not stable for the standard sessions that bracketed the card removal session. Both cells were recorded from the animal that tore down the card when it was present. The absolute deviation of preferred direction in the 2 standard sessions was $96^{\circ}$ for one cell and $174^{\circ}$ for the other. During the card removal session, the preferred direction shifted $-12^{\circ}$ for one cell and $174^{\circ}$ for the other.

The existence of aberrant responses for directional cells suggests that it may be possible to design behavioral procedures that cause stimulus control over preferred direction to be transferred from the white card to other cues. If there were a way to reliably reduce the control exerted by the white card over time, and to simultaneously increase the control exerted by another stimulus, it would be possible to infer a modifiable (plastic) step in the sequence of computations between sensory events and directional cell firing. 


\section{Discussion}

Sensory control of directional cell firing

In the previous paper (Taube et al., 1990), it was demonstrated that the preferred firing direction of head-direction cells is constant over the area of the cylinder, such that vectors in the preferred direction are parallel. The invariance of preferred direction with location rules out the possibility that the firing of a given cell is triggered whenever the rat's head points toward a discrete stimulus source within the cylinder; if directional cell firing was controlled by pointing to a local feature, preferred direction vectors would be expected to converge. The invariance of preferred direction is, however, compatible with the possibility that the firing of a given cell is triggered whenever the head points toward a stimulus that lies far outside the apparatus. The fact that all preferred directions are equally likely (Taube ct al., 1989) could mcan that cach cell is triggered by a different stimulus (e.g., a sound source or the geomagnetic field), where the stimulus can lie anywhere outside the apparatus.

The purpose of this study was to determine which features of the environment exert control over azimuth-specific firing. To address this issue the animal's environment was manipulated in various ways while the effects on directional cell firing were monitored. In principle, a directional reference could be provided by any nonuniformity in the environment. In our experiments, the only intentional asymmetry was the white cue card attached to the cylinder wall. It was found that rotations of this stimulus almost always caused near-equal rotations of the preferred direction. It is important to note that the card controlled the preferred direction for all cells, and not just for cells that had preferred directions pointing toward the cue card. The control exerted by the cue card over preferred direction was not perfect. Nevertheless, the summed control exerted by any unrotated asymmetries must be small, and the possibility that directional cells are exclusively triggered by a distant stimulus source is ruled out. In particular, we have no evidence that the geomagnetic field is important. This finding is important because there are reports that magnetic fields can be detected by many different species (see Mather, 1984, for a review), and several studies have shown that rodents are capable of using the Earth's magnetic field to guide their spatial behavior (Bovet, 1965; Mather and Baker, 1980, 1981).

Taken together, the locational invariance of preferred direction and the stimulus control exerted by the white card indicate that head-direction cells are not triggered when the rat's head points to any discrete stimulus, either local or distant. Headdirection cells are therefore not well described in simple sensory terms. At a minimum, information about the rat's position within the cylinder, the location of a feature of the cue card on the retina, and the position of the eye in the orbit must be combined to generate the observed characteristics of directional cell firing. Thus, the direction-specific firing of directional cells appears based on more complex use of sensory information.

The complexity of the relationship between stimuli and preferred direction is further revealed by the effects of removing the card, the only cuc of known salience. Card removal did not disrupt azimuth-specific firing. Instead, card removal was associated with a rotation of preferred direction, in the absence of any other changes in directional cell firing. The card therefore acts as a reference for the angular coordinate system when present, but it is not necessary to support directional cell firing. The reliable azimuth-specific firing in the absence of the card implies that other stimuli can be used as anchors for dircctional firing when the usual reference is missing. There is an indication that the secondary stimuli that begin to anchor the preferred direction are stable over time; when the card removal experiment was done on cells recorded subsequently from the same animal, there was appreciable consistency of the rotation of preferred direction for the individual cells (Table 2). The consistency of preferred direction rotation after cue removal also indicates that the same secondary stimuli control the firing of all directional cells. This inference is further supported by our findings from simultaneous recordings of cell pairs, where the preferred direction rotation was equal for both cells.

Two observations suggest that other stimuli have effects on directional cell firing even when the white card is present. In the one case when card rotation was done while the animal was present in the cylinder, the preferred direction appeared to show hysteresis. This finding implies that a role was played by secondary cues fixed in the laboratory frame. Second, the deviation of preferred direction from the expected value during card rotation sessions was greater than the deviations from pairs of standard sessions. Thus, other cues in the environment were acting as partial determinants for preferred directional firing. Our experiments were not designed to identify secondary stimuli, but by inference, it seems probable that head-direction cells share with hippocampal place cells the property that their firing is supported by multiple, replaceable cues (O'Keefe and Conway, 1978). The salience of the white card demonstrates that visual stimuli can exert control over directional cell firing, but the role of other sensory modalities remains to be tested.

In addition to local landmarks and global environmental stimuli, directional cell firing could potentially be under the control of internally generated stimuli from the vestibular system, the muscle and joint senses, or corollary motor discharge. In principle, such kinesthetic stimuli could update the current directional heading relative to a reference direction established from external stimuli. Mittelstaedt and Mittelstaedt (1980) have shown that such mechanisms are used by the desert mouse in homing back to its nest. Note, however, that purely kinesthetic guidance could be used only for short times without external references, since errors could not be corrected without feedback from the external world.

In summary, the salience of the white card demonstrates that visual stimuli can exert control over directional cell firing, but the role of other sensory modalities remains to be tested. We have shown that geomagnetic and other stimuli fixed in the laboratory frame do not exert exclusive control over directional cells, but the contribution of distal features is an open and important question.

\section{The reference frame for directional cell firing}

One way that head-direction cells do not confrom to a sensory model concerns the coordinate system that gives the simplest description of firing. For head-direction cells, as with hippocampal place cells (O'Keefe and Dostrovsky, 1971; O'Keefe, 1976), firing rates are most naturally given in terms of external references. The firing of individual cclls varics with head azimuth (a state variable of the animal), but the angular coordinate system itself is fixed in the environment. In contrast, neuronal firing rates in sensory systems are most naturally given in terms of reference to receptive surfaces or the animal per se, at least up to primary and secondary projection areas in isocortex. Directional-sensitive neurons have been reported in other brain 
areas (see Goldberg and Fernandez, 1984; Rose, 1985; Motter et al., 1987; Sikes et al., 1988), but in each case, the directional sensitivity is relative to a reference direction on the receptive surface (i.e., based on the animal as the point of reference). For example, prestriate visual cortex neurons respond best to light patterns that move in a particular direction across their receptive field (Hubel and Wiesel, 1968).

There is no doubt that sense-organ-based information is used in the firing of head-direction cells, but a major informational transformation must occur at or before the postsubiculum. The kind of transformation that is required has been demonstrated by Andersen and colleagues in area 7 a of monkey posterior parietal cortex, where 3 classes of neurons were found (Andersen et al., 1985). One class responded to the position of a stimulus on the retina, and a second class signaled the position of the eyes in the orbit. The properties of the third class of "spatially tuned" neurons were a combination of the properties of the 2 other classes. The spatially tuned cells signaled the location of the stimulus in "head-based" coordinates, although the firing rate of these neurons still varied with the orbital position of the eye. Zipser and Andersen (1988) used a back-propagation method (Rumelhart et al., 1986) to show that the combined signals from units with specific retinal receptive fields and units that reflect eye position provide enough information to produce the firing of the spatially tuned neurons. This finding indicates how the informational content is transformed from a receptor surface-based signal into a level of higher abstract spatial relationships. The study by Zipser and Andersen (1988) suggests that it will be possible to simulate directional cell firing by taking into account variations in the retinal image of the cue card due to the animal's location and orientation and the orbital position of the eye.

\section{Motor correlates of directional cell firing}

Direct observation revealed no obvious relationship between head-direction cell firing and any aspect of the animal's behavioral state except head direction (Taube et al., 1990). It is still possible, however, that head-direction cells are high-order motor cells that cause the animal's head to point in a certain direction. This hypothesis is ruled out, however, by the observation that directional cell firing was the same when the rat was passively carried by hand as when the rat moved by itself. The same observation makes it extremely unlikely that directional cell firing is a corollary motor discharge that signals when the rat moves its head to a particular angle. We conclude that direct or indirect motor influences play at most a secondary role in directional cell firing.

\section{Comparisons of head-direction cells and hippocampal place cells}

Directional cells and place cells share the critical property that the firing of both classes is best described in terms of the animal's spatial relationship to its environment. The major firing correlates of the 2 classes are complementary, however, at least under the behavioral conditions used in the present studies. As reported here, directional cell firing is nearly independent of the animal's location. In contrast, place cell firing in the same cylinder depends almost exclusively on the animal's location and is uncoupled from head direction (Muller et al., 1987; Bostock et al., 1988). It is important to note, however, that directionalinvariance is not a fixed feature of place cell firing; individual cells tend to be more active as a rat moves in or out of an arm on an 8-arm radial maze (McNaughton et al., 1983; Bostock et al., 1988; Leonard et al., 1988).

Despite the major difference in primary firing correlate, directional and place cells respond in virtually identical ways to rotation or removal of the white card. For place cells, card rotation leads to equal rotation of the angular location of the intense firing region (the firing field), and card removal leaves the place field intact except for an unpredictable rotation (Muller and Kubie, 1987). Thus, the cue card anchors the angular location of place cell firing in the same way it acts as a reference for the preferred direction of directional cells, but in neither case does its removal cause a breakdown of fring specificity.

In contrast to the similarity of the responses of directional and place cells to card manipulations, changes in the shape of the apparatus have much more profound effects on the firing of place cells. Muller and Kubie (1987) reported that the locationspecific firing of an individual place cell in the rectangular apparatus could not be predicted from a knowledge of its spatial firing pattern in the cylinder. Specifically, for cells that had a firing field in both apparatuses, there was no relationship that transformed one field into the other that held across cells. In addition, it was often observed that a cell with a firing field in one apparatus was virtually silent in the other apparatus (Kubie and Ranck, 1983; Muller and Kubie, 1987). Thompson and Best (1989) estimate that as few as $25 \%$ of the place cells may be firing in a given environment. Muller and Kubie (1987) concluded that the place cell population underwent a complete remapping after changes in apparatus shape.

In our experiments, changes in shape of the environment led only to changes in the preferred direction of directional cells. There was no analog of the cessation of firing that was sometimes observed in differently shaped apparatuses for place cells. Peak firing rate, directional firing range, and the asymmetry of the firing-rate/head-direction function were unchanged across differently shaped apparatuses. The shift in the preferred direction is noteworthy when considering that both the rectangle and square had a white card in a similar reference position as in the cylinder, and the card could be shown to exert control over directional cell firing in the rectangle and square. In summary, it appears that major changes of the environment affect both head-direction and place cells, but it appears that the effects on place cells are more profound.

The equal rotations of the preferred direction from pairs of simultaneously recorded directional cells under all circumstances suggest that the mapping of directional cells onto the environment is fixed. O'Keefe (1979) concluded that different environments use different subsets from the same total population of place cells, and that the subset of cells mapping one environment overlaps with the subset of cells mapping a second environment. Our findings that directional cells always remained active following environmental manipulations implies that, in contrast to place cells, the postsubiculum uses the same set of directional cells for mapping the angular coordinate system in different environments. Thus, the overall reference direction for azimuth-specific firing may rotate, but the firing properties of individual cells and the relationships between preferred directions of different head-direction cells remain constant. However, these conclusions must be considered tentative, until the origins of the few observed "aberrant" responses are known.

Our observation that the preferred direction of pairs of simultaneously recorded directional cells remained in register 
across different environmental manipulations suggest that the organization of the directional cell network in the postsubiculum is similar in different environmental contexts. This in-register property has also been reported for pairs of hippocampal place cells recorded simultaneously following rotations of the environment (O'Keefe and Speakman, 1987; E. M. Bostock, R. U. Muller, and J. L. Kubie, unpublished observations). It would be of interest to know whether preferred directions and firing fields rotate together after card rotations or card removal. Note, however, that the finding that hippocampal place cells can become silent in a differently shaped environment suggests that place ccll and dircction cell firing can be uncoupled.

\section{The use of direction for guiding locomotive behavior}

The directional signal encoded in head-direction cell firing might be used by the animal in 2 different ways. First, head-direction cell activity could provide information about azimuth during navigation and aid the animal in solving spatial problems. In this case, it would be expected that rats could learn to go in a particular direction, such that their movements would be parallel from any starting position. Despite the extensive amount of literature on the spatial problem-solving abilities of rats, there are relatively few studies devoted to whether rats can use a purely directional strategy in performing a spatial task. In a preliminary study, Stewart and Kubie (1985) trained rats to run in a particular direction on an 8-arm radial maze platform with the maze placed at different locations in a large room. They then tested the rats with the maze at novel locations in the room. Two rats reliably went out on the correct arm during such probe trials. This preliminary result warrants further consideration in light of the existence of head-direction cells. Two field studies of related interest have shown that rodents can use the position of the sun as a compass for homeward orientation (Fluharty et al., 1976; Haigh, 1979). These 3 studies suggest that rodents possess a "sense of direction."

The second way in which directional cell firing could enhance the spatial problem-solving abilities of rats is the possibility that the directional cells in the postsubiculum can represent angular relationships among external objects. In behavioral terms, this is an important issue, since an ability to guide locomotion according to an external angular coordinate system would make available a simple, geometric computation by which a rat could get to a distant, unseen goal or take a short cut when it becomes available.

Another interesting issue is how the head-direction cell and place cell representations of the environment interact. Some data that address this question come from studies of bird homing and migration, in which the control of flight direction is often distinguished from knowledge of places. Bingman et al. (1984) showed that homing pigeons with bilateral lesions of the hippocampal analog can find their way back to the general locale of their homes when released 20 miles away. Nevertheless, they were impaired relative to normal pigeons, in that they could not find their exact home cage. These findings suggest that the directional system is intact after hippocampal lesions, such that the birds can correctly navigate back to the vicinity of their home cage. Under the assumption that the avian hippocampal analog has functions similar to the rat hippocampus, it is also understandable why the damaged animals were unable to precisely relocate their home cages. This interpretation implies a dissociation (uncoupling) between the directional and place sys- tems in the homing piegon and suggests that it would be worthwhile to do similar experiments in the rat.

Although it is possible to dissociate the directional and location systems, we imagine that under ordinary circumstances they act together. This is suggested by the similar cffects of cue card manipulations on place cells and head-direction cells. Entorhinal cortex is one possible site for such an interaction, since it receives input from both the hippocampus and the postsubiculum. A second possibility is retrosplenial cortex, which receives direct input from the postsubiculum and input from the hippocampus relayed through the subiculum. Finally, because the postsubiculum receives input from the subiculum, the site of interaction could also be cells in the postsubiculum (for a discussion of the anatomical projections of the postsubiculum, see Discussion of Taube et al., 1990).

We also imagine that the directional and locational systems serve different functions for guiding locomotion, even when they are cooperating. In this behavioral scheme, directional cells provide the wherewithal for long-range navigation, whereas place cells provide for local navigation. One possibility is that the place cell mapping represents a locale (a continuous region of space) whose size is about equal to the size of the current visual boundaries (O'Keefe and Nadel, 1978). A directional cell mapping system that extends over much larger distances could be enough to efficiently solve the problem of getting from one locale to another. This idea is consistent with the effects of hippocampal lesions in rats and can be tested by observing the behavioral effects of postsubicular lesions.

\section{References}

Andersen, R. A., G. K. Essick, and R. M. Siegel (1985) Encoding of spatial location by posterior parietal neurons. Science $230: 456-458$.

Best, P., and R. F. Thompson (1984) Hippocampal cells which have place field activity also show changes in activity during classical conditioning. Soc. Neurosci. Abstr. 10: 125.

Bingman, V., P. Bagnoli, P. Ioale, and J. Casini (1984) Homing behavior of pigeons after telencephalic ablations. Brain Behav. Evol. 24: 94-108.

Bostock, E. M., J. S. Taube, and R. U. Muller (1988) The effects of head orientation of the firing of hippocampal place cells. Soc. Neurosci. Abstr. 14: 127.

Bovet, J. (1965) Ein versuch, wilde mause unter ausschluss optischer, akustischer und osmischer merkmale auf himmelsrichtungen zu dressieren. Z. Tierpsychol. 22: 839-859.

Breese, C. R., R. E. Hampson, and S. A. Deadwyler (1989) Ilippocampal place cells: Stereotypy and plasticity. J. Neurosci. 9: 10971111.

Fluharty, S. L., D. H. Taylor, and G. W. Barrett (1976) Sun compass orientation in the meadow vole, Microtus pennsylvanicus. J. Mammal. 57: $1-9$.

Goldberg, J. M., and C. Fernandez (1984) The vestibular system. In Handbook of Physiology. Section 1. The Nervous System. Vol. III. Sensory Processes, Part 2, J. M. Brookhart, S. Geiger, I. Darian-Smith, and V. Mountcastle, eds., pp. 977-1022, American Physiological Society, Bethesda, MD.

Haigh, G. R. (1979) Sun-compass orientation in the thirteen-lined ground squirrel, Spermophilus tridecemlineatus. J. Mammal. 60:629632.

Hubel, D. H., and T. N. Wiesel (1968) Receptive ficlds and functional architecture of monkey striate cortex. J. Physiol. 195: 215-243.

Kubie, J. L., and J. B. Ranck, Jr. (1983) Sensory-behavioral correlates in individual hippocampal neurons in three situations: Space and context. In Neurobiology of the Hippocampus, W. Seifert, ed., pp. 433-447, Academic, New York.

Leonard, B. J., B. L. McNaughton, and C. A. Barnes (1988) Locationand direction-specific discharge of rat hippocampal complex-spike 
cells in an open field and on the radial 8-arm maze. Soc. Neurosci. Abstr. 14: 396.

Mather, J. G. (1984) Magnetoreception and the search for magnetic material in rodents. In Magnetite Biomineralization and Magnetoreception in Organisms. A New Biomagnetism, J. L. Kirschvink, D. S. Jones, and B. J. MacFadden, eds., pp. 509-533, Plenum, New York.

Mather, J. G., and R. R. Baker (1980) A demonstration of navigation by small rodents using an orientation cage. Nature 284: 259-262.

Mather, J. G., and R. R. Baker (1981) Magnetic sense of direction in woodmice for route-based navigation. Nature 291: 152-155.

McNaughton, B. L., C. A. Barnes, and J. O'Keefe (1983) The contributions of position, direction and velocity to single unit activity in the hippocampus of freely moving rats. Exp. Brain Res. 52: 41-49.

Mittelstaedt, M.-L., and H. Mittelstaedt (1980) Homing by path in tegration in a mammal. Naturwissenschaften 67: 566-567.

Motter, B. C., M. A. Steinmetz, C. J. Duffy, and V. B. Mountcastle (1987) Functional properties of parietal visual neurons: Mechanisms of directionality along a single axis. J. Neurosci. 7: 154-176.

Muller, R. U., and J. L. Kubie (1987) The effects of changes in the environment on the spatial firing of hippocampal complex-spike cells. J. Neurosci. 7: 1951-1968.

Muller, R. U., J. L. Kubie, and J. B. Ranck, Jr. (1987) Spatial firing patterns of hippocampal complex-spike cells in a fixed environment. J. Neurosci. 7: 1935-1950.

O'Keefe, J. (1976) Place units in the hippocampus of the freely moving rat. Exp. Neurol. 51: 78-109.

O'Keefe, J. (1979) A review of the hippocampal place cells. Prog. Neurobiol. 13: 419-439.

O'Keefe, J., and D. H. Conway (1978) Hippocampal place units in the freely moving rat: Why they fire where they fire. Exp. Brain Res. 31: 573-590.

O'Keefe, J., and J. Dostrovsky (1971) The hippocampus as a spatial map. Preliminary evidence from unit activity in the freely-moving rat. Brain Res. 34: 171-175.
O'Keefe, J., and L. Nadel (1978) The Hippocampus as a Cognitive Map. Clarendon, Oxford, U.K.

O'Keefe, J., and A. Speakman (1987) Single unit activity in the rat hippocampus during a spatial memory task. Exp. Brain Res. 68: 127.

Rose, J. D. (1985) Dorsal-ventral differences in the midbrain distribution of single neurons with head movement-correlated and locomotion-correlated firing in the golden hamster. Exp. Neurol. 87:225234.

Rumelhart, D. E., G. E. Hinton, and R. J. Williams (1986) Learning internal representations by error propagation. In Parallel Distributed Processing: Explorations in the Microstructure of Cognition. Vol. I. Foundations, D. E. Rumelhart and J. L. McClelland, eds., pp. 318362, MIT, Cambridge.

Sikes, K. W., B. A. Vogt, and H. A. Swadlow (1988) Neuronal responses in rabbit cingulate cortex linked to quick-phase eye movements during nystagmus. J. Neurophysiol. 59: 922-936.

Stewart, M., and J. L. Kubie (1985) Can rats learn a compass direction? Eastern Psychiatry Assoc. 56: 32.

Taube, J. S., R. U. Muller, and J. B. Ranck, Jr. (1987) A quantitative analysis of head-direction cells in the postsubiculum. Soc. Neurosci. Abstr. 13: 1332.

Taube, J. S., R. U. Muller, and J. B. Ranck, Jr. (1988) Effects of environmental manipulations on head-direction cell firing. Soc. Neurosci. Abstr. 14: 126.

Taube, J. S., R. U. Muller, and J. B. Ranck, Jr. (1990) Head-direction cells recorded from the postsubiculum in freely moving rats. I. Description and quantitative analysis. J. Neurosci. 10:420-435.

Thompson, L. 'T., and P. J. Best (1989) Place cells and silent cells in the hippocampus of freely-behaving rats. J. Neurosci. 9: 2382-2390.

Zipser, D., and R. A. Andersen (1988) A back-propagation programmed network that simulates response properties of a subset of posterior parietal neurons. Nature 331: 679-684. 